\title{
Draft genome sequence of Dyadobacter tibetensis type strain (Y620-1) isolated from glacial ice
}

\author{
Yongqin Liu ${ }^{1 *}$, Anyi Hu${ }^{2}$, Liang Shen 1 , Tandong Yao ${ }^{1}$, Nianzhi Jiao ${ }^{3}$, Ninglian Wang ${ }^{4}$, Baiqing \\ $\mathrm{Xu}^{1}$ \\ ${ }^{1}$ Key Laboratory of Tibetan Environmental Changes and Land Surface Processes, Institute of \\ Tibetan Plateau Research, Chinese Academy of Sciences, Beijing, China \\ ${ }^{2}$ Key Laboratory of Urban Environment and Health, Institute of Urban Environment, Chi- \\ nese Academy of Sciences, Xiamen, China \\ ${ }^{3}$ State Key Laboratory of Marine Environmental Science, Xiamen University, Xiamen, China \\ ${ }^{4}$ Cold and Arid Regions Environmental and Engineering Research Institute, Chinese Acade- \\ my of Sciences, Lanzhou, China \\ *Correspondence: Liu yongquin (yqliu@itpcas.ac.cn)
}

Keywords: Dyadobacter tibetensis, draft genome, psychrotolerant bacterium, glacial ice

Dyadobacter tibetensis Y $620-1$ is the type strain of the species Dyadobacter tibetensis, isolat-
ed from ice at a depth of $59 \mathrm{~m}$ from a high altitude glacier in China ( $5670 \mathrm{~m}$ above sea level).
It is psychrotolerant with growth temperature ranges of 4 to $35^{\circ} \mathrm{C}$. Here we describe the fea-
tures of this organism, together with the draft genome sequence and annotation. The
$5,313,963$ bp long genome contains 4,828 protein-coding genes and $39 \mathrm{RNA}$ genes. To the
best of our knowledge, this is the first Dyadobacter strain that was isolated from glacial ice.
This study provides genetic information of this organism to identify the genes linked to its
specific mechanisms for adaption to extreme glacial environment.

\section{Introduction}

Strain Y620-1 (=JCM 18589= CGMCC 1.12215T) is the type strain of the species Dyadobacter tibetensis [1]. The genus Dyadobacter currently has 12 species after it was first proposed by Chelius and Triplett on 2000, and the type species is D. fermentans [2]. Those species isolated from diverse environment, i.e. glacial ice, soil from the Arctic, Colorado Plateau, farm and a ginseng field, desert sand, freshwater and sea water, and plant material [1-12]. So far, however, the genome sequences have been determined for only three Dyadobacter strains (D. alkalitolerans DSM 23607 (GCA_000428845), D. fermentans DSM 18053 (GCA_000023125), D. beijingensis DSM 21582 (GCA_000382205)), and only the complete genome sequence of $D$. fermentans DSM 18053 has been published [13].

D. tibetensis strain Y620-1 was isolated from $59 \mathrm{~m}$ depth section of an $122 \mathrm{~m}$ ice core drilled from Yuzhufeng Glacier at $5670 \mathrm{~m}$ above sea level, Tibetan Plateau, China [1]. Glacier ice is an extreme environment with low temperature and nutrients, but high UV radiation, and is a huge reservoir of extremophilic microorganism that have accumulated for hundreds of years [14]. Diverse isolates were recovered from glacial ice, but the genomes of bacteria in the extreme environment were limited $[15,16]$. Here, we present the genome sequence of psychrotolerant $D$. tibetensis strain Y620-1 isolated from ice core. This is the first genome sequence of a bacterial isolated from a deep high altitude glacier ice.

\section{Classification and features}

The phylogenetic position of genus Dyadobacter is in the Cytophagaceae, a very diverse family within the order Sphingobacteriales, the phylum Bacteroidetes [13]. Closest related genera are Persicitalea and Runella [13]. D. tibetensis strain Y620-1 represents a novel species of the genus Dyadobacter based on reported genotypic and phenotypic feature [1].

Strain Y620-1 was isolated at $4^{\circ} \mathrm{C}$ incubation from ice core melt water cultivated on R2A medium 
[17]. It was Gram-stain-negative, non-motile and rod-shaped with $1 \mu \mathrm{m}$ to $2 \mu \mathrm{m}$ length [1] (Figure 1). Colonies are yellow, round, smooth, convex and opaque on R2A after incubation at $30^{\circ} \mathrm{C}$ for $2-$ 3 days. Growth occurs at $4-35^{\circ} \mathrm{C}$ on $\mathrm{R} 2 \mathrm{~A}$, with an optimum at $30^{\circ} \mathrm{C}$. It produces a flexirubin-like pigment, the same as the other species in the genus. The major fatty acids are summed feature 3 $\left(\mathrm{C}_{16: 1 \omega 7 \mathrm{c}}\right.$ and/or iso- $\left.\mathrm{C}_{15: 0,2-\mathrm{OH}}\right)$, iso- $\mathrm{C}_{15: 0}, \mathrm{C}_{16: 1 \omega 5 \mathrm{c}}$ and iso- $\mathrm{C}_{17:} 0$ 3-он. The predominant polar lipid is phosphatidylethanolamine [1].The important characteristics of the strain based on literature descriptions are summarized in Table 1 . The strain exhibited a 16S rRNA gene sequence similarity with other members of the genus Dyadobacter ranging from $95.1 \%$ with $D$. ginsengisoli Gsoil 043 to $93.6 \%$ with $D$. beijingensis A54 (Figure 2).

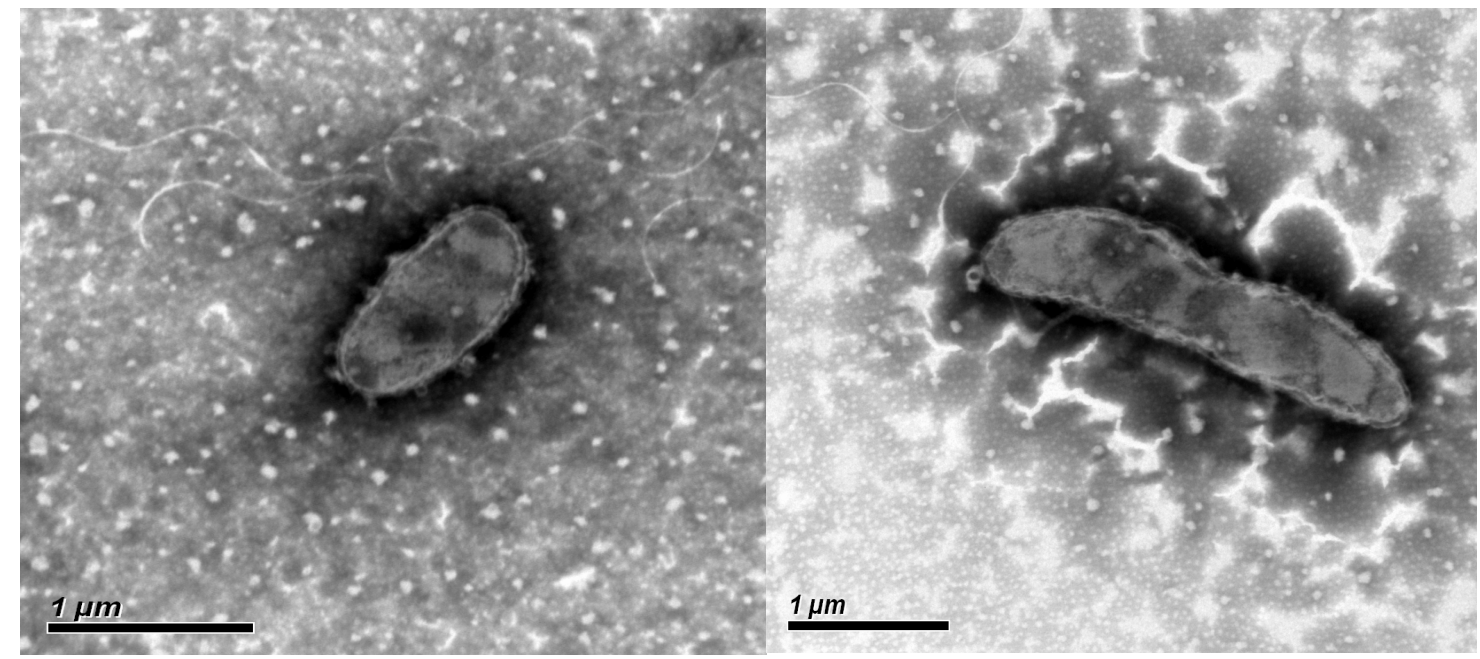

Figure 1 Transmission electron micrograph of Dyadobacter tibetensis (T) Y620-1

The utilization of carbon compounds by strain Y620-1 was determined using Generation-III microplates on an OmniLog phenotyping device (BIOLOG Inc., Hayward, CA, USA). The microplates were inoculated at $30^{\circ} \mathrm{C}$ with a cell suspension at a cell density of $95-96 \%$ turbidity and dye IF-A. Strain Y620-1 assimilates dextrin, D-maltose, Dtrehalose, D-cellobiose, gentiobiose, D-melibiose, D-salicin, N-Acetyl-D-glucosamine, D-mannose, Glycyl-L-proline, L-alanine, L-histidine, L-serine, methyl, pyruvate, L-lactic acid, citric acid, $\alpha$-Ketoglutaric acid, L-malic acid, propionic acid and acetic acid, but not stachyose, D-raffinose,N-Acetyl- $\beta$ dmannosamine, N-Acetyl-dgalactosamine, NAcetyl-neuraminic acid, D-galactose, 3-methyl glu- cose, L-fucose, L-rhamnose, inosine, D-sorbitol, Dmannitol, D-arabitol, myo-Inositol, glycerol, Dglucose-6-P04, D-aspartic acid, gelatin, L-arginine, L-pyroglutamic acid, pectin, L-galactonic acid lactone, D-gluconic acid, glucuronamide, mucic acid, quinic acid, D-saccharic acid, $\beta$-hydroxyphenylacetic acid, D-lactic acid methyl ester, Dmalic acid, $\gamma$-amino-butryric acid, $\beta$-hydroxy- $\mathrm{D}$, $\mathrm{L}$ butyric Acid and formic acid. It is sensitive to minocycline, potassium tellurite, nalidixic acid, lithium chloride, fusidic acid, D-serine and sodium bromate, but not troleandomycin, rifamycin, lincomycin, guanidine $\mathrm{HCl}$, niaproof 4, vancomycin, tetrazolium violet, tetrazolium blue, aztreonam and sodium butyrate. 


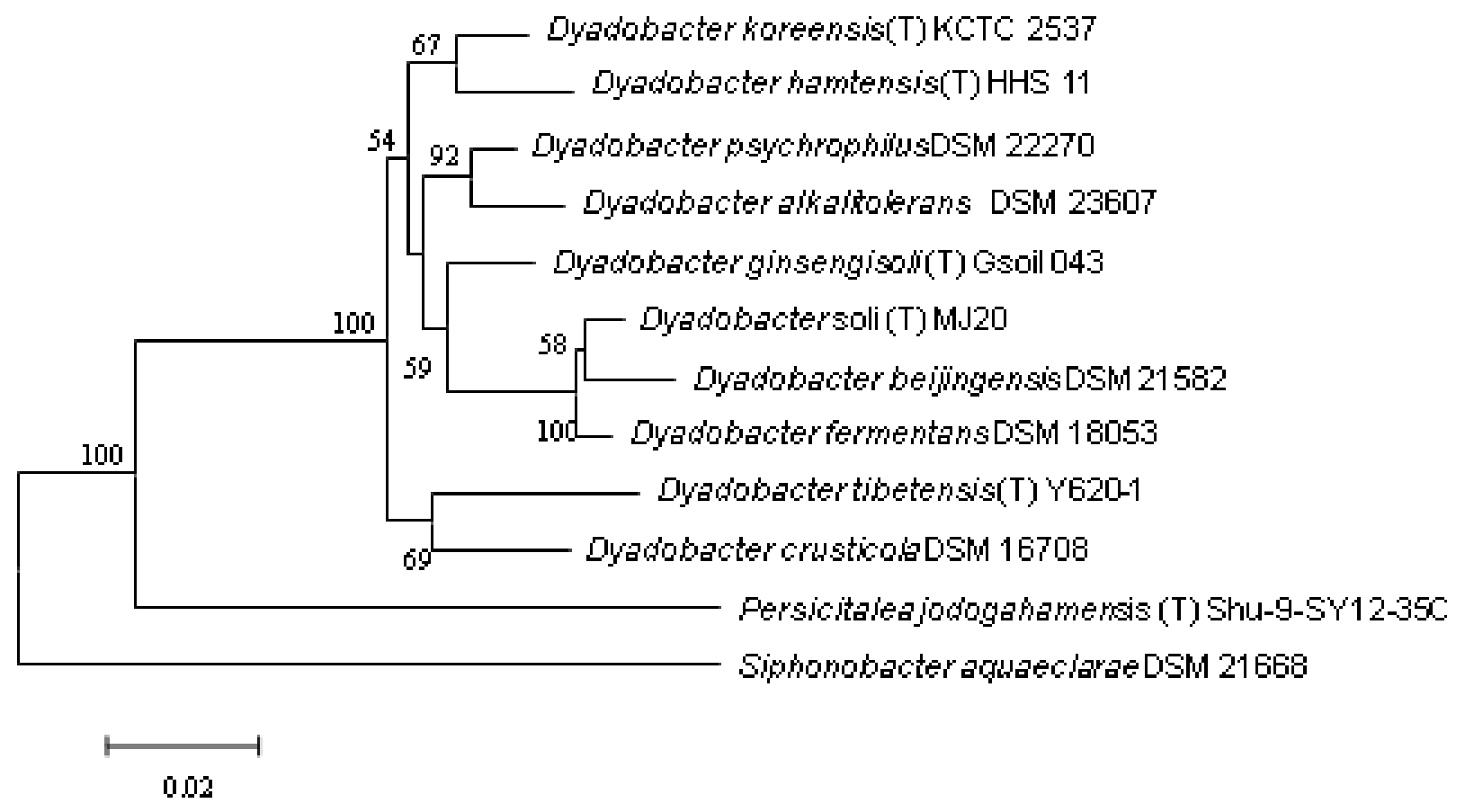

Figure 2. Phylogenetic tree highlighting the position of Dyadobacter tibetensis (T) Y620-1 relative to other type strains within the genus Dyadobacter. Type strains D. alkalitolerans DSM 23607, D. beijingensis DSM 21582 and D. fermentans DSM 18053 are having fully sequenced genomes with assigned GenBank Assembly ID GCA_000428845.1, GCF_000382205.1 and GCA_000023125.1. The type strains and their corresponding GenBank accession numbers for 16S rRNA genes are: D. ginsengisoli Gsoil 043(T), AB245369; D. crusticola, DSM 16708, AJ821885; D. alkalitolerans DSM 23607, EU360597; D. psychrophilus DSM 22270, GQ131577; D. koreensis KCTC 12534(T), EF017660; D. soli MJ20(T), GQ241324; D. fermentans DSM 18053, CP001619; D. hamtensisHHS 11(T), AJ619978; D. beijingensis DSM 21582, DQ335125; Persicitalea jodogahamensis (T) Shu-9SY12-35C, AB272165. The tree uses sequences aligned by the RDP aligner, and uses the Jukes-Cantor corrected distance model to construct a distance matrix based on alignment model positions without the use of alignment inserts, and uses a minimum comparable position of 200. The tree was built with RDP Tree Builder, which uses Weighbor [21] with an alphabet size of 4 and length size of 1000. Building of the tree also involves a bootstrapping process repeated 100 times to generate a majority consensus tree [22]. Siphonobacter aquaeclarae DSM 21668, FJ177421, was used as an out group. 
Table 1. Classification and general features of Dyadobacter tibetensis (T) Y620-1 according to the MIGS recommendations

\begin{tabular}{|c|c|c|c|}
\hline MIGS ID & \multirow[t]{2}{*}{ Property } & Term & $\begin{array}{r}\text { Evidence } \\
\text { code }^{\mathrm{a}}\end{array}$ \\
\hline & & Domain Bacteria & \\
\hline & \multirow{7}{*}{ Current classification } & Phylum Bacteroidetes & TAS [18] \\
\hline & & Class Sphingobacteria & TAS [18] \\
\hline & & Order Sphingobacteriales & TAS [18] \\
\hline & & Family Cytophagaceae & TAS [18] \\
\hline & & Genus Dyadobacter & TAS [19] \\
\hline & & Species Dyadobacter tibetensis & TAS [2] \\
\hline & & Type strain Y620-1 & TAS [1] \\
\hline & Gram stain & Negative & TAS [1] \\
\hline & Cell shape & Rod & TAS [1] \\
\hline & Motility & Nonmotile & TAS [1] \\
\hline & Sporulation & Non-sporulating & TAS [1] \\
\hline & Temperature range & $4-35^{\circ} \mathrm{C}$ & TAS [1] \\
\hline & Optimum temperature & $30^{\circ} \mathrm{C}$ & TAS [1] \\
\hline & Carbon source & glucose, arabinose, mannitol mannose & TAS [1] \\
\hline & Energy source & Not reported & NAS \\
\hline \multirow[t]{2}{*}{ MIGS-6 } & Habitat & $59 \mathrm{~m}$ depth section of $122 \mathrm{~m}$ ice core & TAS [1] \\
\hline & Salinity & & \\
\hline \multirow[t]{2}{*}{ MIGS-6.3 } & \multirow{3}{*}{ Oxygen } & $0-5 \%(\mathrm{NaCl} \mathrm{m} / \mathrm{v})$ & TAS [1] \\
\hline & & & \\
\hline MIGS-22 & & Aerobic & TAS [1] \\
\hline MIGS-15 & Biotic relationship & free-living & TAS [1] \\
\hline MIGS-14 & Pathogenicity & Not reported & NAS \\
\hline MIGS-4 & Geographic location & China & TAS [1] \\
\hline MIGS-5 & Sample collection time & 2010 & IDA \\
\hline MIGS-4.1 & Latitude & $94^{\circ} 14.77^{\prime} \mathrm{E}$ & TAS [1] \\
\hline MIGS-4.2 & Longitude & $35^{\circ} 39.64^{\prime} \mathrm{N}$ & TAS [1] \\
\hline MIGS-4.3 & Depth & $59 \mathrm{~m}$ & TAS [1] \\
\hline MIGS-4.4 & Altitude & $5670 \mathrm{~m}$ above sea level & IDA \\
\hline
\end{tabular}

a) Evidence codes - IDA: Inferred from Direct Assay; TAS: Traceable Author Statement (i.e., a direct report exists in the literature); NAS: Non-traceable Author Statement (i.e., not directly observed for the living, isolated sample, but based on a generally accepted property for the species, or anecdotal evidence). These evidence codes are from the Gene Ontology project [20].

\section{Genome sequencing information} Genome project history

The organism was selected for sequencing on the basis of it from extreme deep ice core from high altitude glacier. The shotgun genome sequencing project was completed in December 2012 and has been deposited at DDBJ/EMBL/GenBank under the accession number AZQN00000000. The version described here is the first version, AZQN01000000. The genome sequencing was carried out in Shanghai Majorbio Bio-pharm Technology Co., Ltd (Shanghai, China). A summary of the project information is shown in Table 2 


\begin{tabular}{|c|c|c|}
\hline MIGS ID & Property & Term \\
\hline \multirow[t]{2}{*}{ MIGS-31 } & Finishing quality & High-quality draft \\
\hline & & Two illumina paired-end libraries \\
\hline MIGS-28 & Libraries used & (170 bp and 800 bp insert size) \\
\hline MIGS-29 & Sequencing platforms & Illumina GAllx \\
\hline MIGS-31.2 & Fold coverage & $384 \times$ \\
\hline MIGS-30 & Assemblers & SOAPdenovo v1.05 \\
\hline \multirow[t]{4}{*}{ MIGS-32 } & Gene calling method & Glimmer3, RAST \\
\hline & Genbank ID & AZQN00000000 \\
\hline & Genbank Date of Release & January 31, 2014 \\
\hline & NCBI project ID & PRJNA230913 \\
\hline \multirow[t]{2}{*}{ MIGS-13 } & Source material identifier & CGMCC 1.12215 \\
\hline & Project relevance & Glacial microbial ecology \\
\hline
\end{tabular}

\section{Growth conditions and DNA isolation}

Cells of strain Y620-1 were harvested from R2A broth following 2 days incubation at $30{ }^{\circ} \mathrm{C}$ with shaking at $180 \mathrm{rpm}$. The genomic DNA of the strain was extracted according to the method previously described by Marmur et al. [23]. Extraction was started with $100 \mathrm{ml}$ of $48 \mathrm{~h}$ culture, centrifuged at $4{ }^{\circ} \mathrm{C}$ and $10,000 \mathrm{rpm}$ for $15 \mathrm{~min}$. Then, cells were washed three times with $5 \mathrm{ml}$ sterile water. The washed cells were resuspended in $1,128 \mu \mathrm{L}$ Tris-HCl buffer $(10 \mathrm{mM})$ containing 1 mM EDTA (pH 8.0) and $20 \mu \mathrm{g}$ lysozyme and incubated at $37{ }^{\circ} \mathrm{C}$ for $2 \mathrm{~h}$. followed by adding of $6 \mu \mathrm{L}$ proteinase $\mathrm{K}(20 \mathrm{mg} / \mathrm{mL}), 4 \mu \mathrm{L}$ DNase-free RNase $(10 \mathrm{mg} / \mathrm{mL}), 100 \mu \mathrm{L}$ SDS (20\% w/v) and the cell suspension was incubated at $55^{\circ} \mathrm{C}$ for $3 \mathrm{~h}$. The cell lysate was extracted twice with phenol/chloroform/isoamyl alcohol (25:24:1) and once with chloroform/isoamyl alcohol (24:1), and the aqueous layer was separated after centrifugation at 12,000 rpm for $15 \mathrm{~min}$. The DNA was precipitated with 1 volumes of frozen anhydrous ethanol. The purity of genomic DNA was assessed by NanoDrop (2000c, Thermo) with OD 260:280 ratio of 1.8-2. The DNA was stock in TE (pH 8.0) for genome sequencing.

\section{Genome sequencing and assembly}

The genome of strain Y620-1 was sequenced using an Illumina GAIIx instrument with two paired-end libraries (170 bp and 800 bp insert size). The raw sequencing data was processed to discard reads containing adaptor sequences, a high rate of ambiguity, and removing the sequence reads which were of low quality. A total of 2,041 Mb highquality of Illumina data were obtained, providing approximately 384-fold coverage. The high- quality reads were assembled in silico using SOAPdenovo v1.05, resulting in 33 contigs $(>200$ bp) with an N50 length of 797,100 bp.

\section{Genome annotation}

The coding sequences (CDS) were predicted using Glimmer 3.02 [24], while tRNAscan-SE [25] and RNAmmer [26] were used to identify tRNA and rRNA, respectively. The genome sequence was also uploaded into the Rapid Annotation using Subsystem Technology (RAST) system [27] to check the annotated sequences. The functions of predicted protein-coding genes were then annotated through comparisons with the databases of NCBINR [28], COG [29], and KEGG [30]. The program TMHMM [31] and SignalP [32] were used to identify putative transmembrane helices and signal peptides.

\section{Genome properties}

The Y620-1 draft genome sequence has a total of $5,313,963$ bp with an average GC content of $43.44 \%$. There are 4,867 predicted genes, of which 4,828 are protein-coding genes, and 39 are RNA genes. A total of 2,844 genes (58.91\%) are assigned a putative function. The remaining genes were annotated as either hypothetical proteins or proteins of unknown functions. Using COG functional assignment, $70.55 \%$ of protein coding genes could be classified into 20 COG categories. The properties and the statistics of the genome are summarized in Tables 3 and 4. According to the subsystem-based annotation generated by RAST, $\sim 32 \%$ protein-coding genes of strain Y620-1 could be assigned to 358 metabolic subsystems. The most abundant of the subsystems are related to carbohydrates $(\mathrm{n}=323,7.2 \%$ of total protein- 
coding genes), following by amino acids and derivatives $(n=272,6.0 \%)$, cofactors, vitamins, prosthetic groups, pigments $(n=184,4.1 \%)$, protein metabolism ( $\mathrm{n}=143,3.2 \%)$, membrane transport $(132,2.9 \%)$ and respiration $(131,2.9 \%)$.

Table 3. Nucleotide content and gene count levels of the genome

\begin{tabular}{lrr}
\hline Attribute & Value & \% of total \\
\hline Genome size (bp) & $5,313,963$ & 100 \\
DNA coding region (bp) & $4,680,447$ & 88.08 \\
DNA G+C content (bp) & $2,308,448$ & 43.44 \\
Total genes & 4,867 & 100 \\
RNA genes & 39 & 0.80 \\
Protein-coding genes & 4,828 & 82.68 \\
Genes with function prediction & 2,844 & 58.91 \\
Genes assigned to COGs & 2,208 & 70.55 \\
Genes assigned to Pfam domains & 3299 & 68.33 \\
Genes assigned to TIGRfam domains & 2161 & 44.76 \\
Genes with signal peptides & 372 & 7.71 \\
Genes with transmembrane helices & 628 & 13.01 \\
CRISPR repeats & 1 & \\
\hline
\end{tabular}

a) The total is based on either the size of the genome in base pairs or the total number of protein coding genes in the annotated genome.

Table 4. Number of genes associated with the 25 general COG functional categories

\begin{tabular}{|c|c|c|c|}
\hline Code & Value & \%age ${ }^{a}$ & Description \\
\hline$J$ & 149 & 3.09 & Translation \\
\hline A & 0 & - & RNA processing and modification \\
\hline K & 261 & 5.14 & Transcription \\
\hline $\mathrm{L}$ & 130 & 2.69 & Replication, recombination and repair \\
\hline B & 0 & - & Chromatin structure and dynamics \\
\hline $\mathrm{D}$ & 22 & 0.46 & Cell cycle control, mitosis and meiosis \\
\hline $\mathrm{Y}$ & 0 & - & Nuclear structure \\
\hline $\mathrm{V}$ & 61 & 1.26 & Defense mechanisms \\
\hline $\mathrm{T}$ & 217 & 4.49 & Signal transduction mechanisms \\
\hline M & 288 & 5.97 & Cell wall/membrane biogenesis \\
\hline $\mathrm{N}$ & 12 & 0.25 & Cell motility \\
\hline Z & 1 & 0.02 & Cytoskeleton \\
\hline W & 0 & - & Extracellular structures \\
\hline$U$ & 52 & 1.08 & Intracellular trafficking and secretion \\
\hline $\mathrm{O}$ & 109 & 2.26 & Posttranslational modification, protein turnover, chaperones \\
\hline C & 201 & 4.16 & Energy production and conversion \\
\hline G & 269 & 5.57 & Carbohydrate transport and metabolism \\
\hline $\mathrm{E}$ & 233 & 4.83 & Amino acid transport and metabolism \\
\hline $\mathrm{F}$ & 73 & 1.51 & Nucleotide transport and metabolism \\
\hline $\mathrm{H}$ & 182 & 3.77 & Coenzyme transport and metabolism \\
\hline I & 132 & 2.73 & Lipid transport and metabolism \\
\hline $\mathrm{P}$ & 259 & 5.36 & Inorganic ion transport and metabolism \\
\hline Q & 84 & 1.74 & Secondary metabolites biosynthesis, transport and catabolism \\
\hline $\mathrm{R}$ & 410 & 8.49 & General function prediction only \\
\hline S & 261 & 5.41 & Function unknown \\
\hline- & 1422 & 29.45 & Not in COGs \\
\hline
\end{tabular}

a) The total is based on the total number of protein coding genes in the annotated genome. 


\section{Discussion}

Although there were 12 species assigned to Dyadobacter, only three have a completed genome sequence and are D. alkalitolerans DSM 23607, D. fermentans DSM 18053, and D. beijingensis DSM 21582. Strain Y620-1 has the smallest genome of D. alkalitolerans DSM 23607, D. fermentans DSM 18053 and D. beijingensis DSM 21582 (6.29 Mbp, 6.97 Mbp and 7.37 Mbp, respectively). The GC content of strain Y620-1 is comparable to that of $D$. alkalitolerans DSM 23607 (45.66\%), but lower than those of D. fermentans DSM 18053 (51.54\%) and D. beijingensis DSM 21582 (52.09\%). In order to estimate the similarity among the sequenced Dyadobacter strains, an average nucleotide identity (ANI) and Genome-to-Genome Distance Calculator (GGDC) were calculated using the software JSpecies v1.2 [33] and GGDC v2.0 [34], respectively. Table 5 shows the results of ANI and GGDC.

ANI analysis showed that strain Y620-1 shared a low degree of similarity with other Dyadobacter species ( $<69 \%$ ANIb and < 84\% ANIm), whereas relatively higher ANI value were obtained for $D$. alkalitolerans DSM 23607, D. fermentans DSM
18053 and D. beijingensis DSM 21582 (Table 5). Although the core concept of GGDC was based on 'genome blast distance phylogeny', which is different from ANI [35], GGDC analysis showed similar results. In both analyses, the highest similarity values were observed in the comparisons of $D$. fermentans DSM 18053 with D. beijingensis DSM 21582. These results were in line with phylogeny analysis based on 16S rRNA gene, which shows that D. fermentans DSM 18053 and D. beijingensis DSM 21582 form a cluster with Dyadobacter soli MJ20. Moreover, the comparison of distribution of COG categories in the genome of four Dyadobacter strains revealed that there were significant correlations between the distribution of COG categories of strain Y620-1 and other strains ( $r=0.970$ $0.979)$. However, relatively higher correlation coefficients were observed for D. alkalitolerans DSM 23607 and D. fermentans DSM 18053 (0.988), D. alkalitolerans DSM 23607 and D. beijingensis DSM 21582 (0.991), and D. fermentans DSM 18053 and D. beijingensis DSM 21582 (0.991) (Figure 3).

Table 5. Pairwise comparisons between four Dyadobacter strains using the ANI and GGDC.

\begin{tabular}{|c|c|c|c|c|c|c|}
\hline & & \multicolumn{2}{|c|}{ ANI } & \multicolumn{3}{|c|}{ GGDC } \\
\hline & & $\begin{array}{c}\text { ANIb } \\
(\%)\end{array}$ & $\begin{array}{l}\text { ANIm } \\
(\%)\end{array}$ & $\begin{array}{l}\text { HSP / total } \\
\text { length }(\%)\end{array}$ & $\begin{array}{c}\text { Identities / } \\
\text { HSP } \\
\text { length (\%) }\end{array}$ & $\begin{array}{c}\text { Identities / } \\
\text { total length } \\
(\%)\end{array}$ \\
\hline $\begin{array}{l}\text { D. tibetensis } \\
\text { Y620-1 }\end{array}$ & $\begin{array}{l}\text { D. alkalitolerans } \\
\text { DSM } 23607\end{array}$ & 68.04 & 83.14 & 13 & 18 & 13.3 \\
\hline D. tibetensis & D. fermentans & & & & & \\
\hline Y620-1 & DSM 18053 & 67.86 & 83.88 & 13 & 18.1 & 13.4 \\
\hline D. tibetensis & D. beijingensis & & & & & \\
\hline Y620-1 & DSM 21582 & 67.7 & 83.46 & 13 & 17.4 & 13.3 \\
\hline D. alkalitolerans & D. fermentans & & & & & \\
\hline DSM 23607 & DSM 18053 & 72.89 & 82.23 & 16.5 & 18.2 & 16.3 \\
\hline D. alkalitolerans & D. beijingensis & & & & & \\
\hline DSM 23607 & DSM 21582 & 72.79 & 82.52 & 16.5 & 18.1 & 16.3 \\
\hline D. fermentans & D. beijingensis & & & & & \\
\hline DSM 18053 & DSM 21582 & 81.41 & 85.13 & 40.4 & 25.3 & 35.5 \\
\hline
\end{tabular}




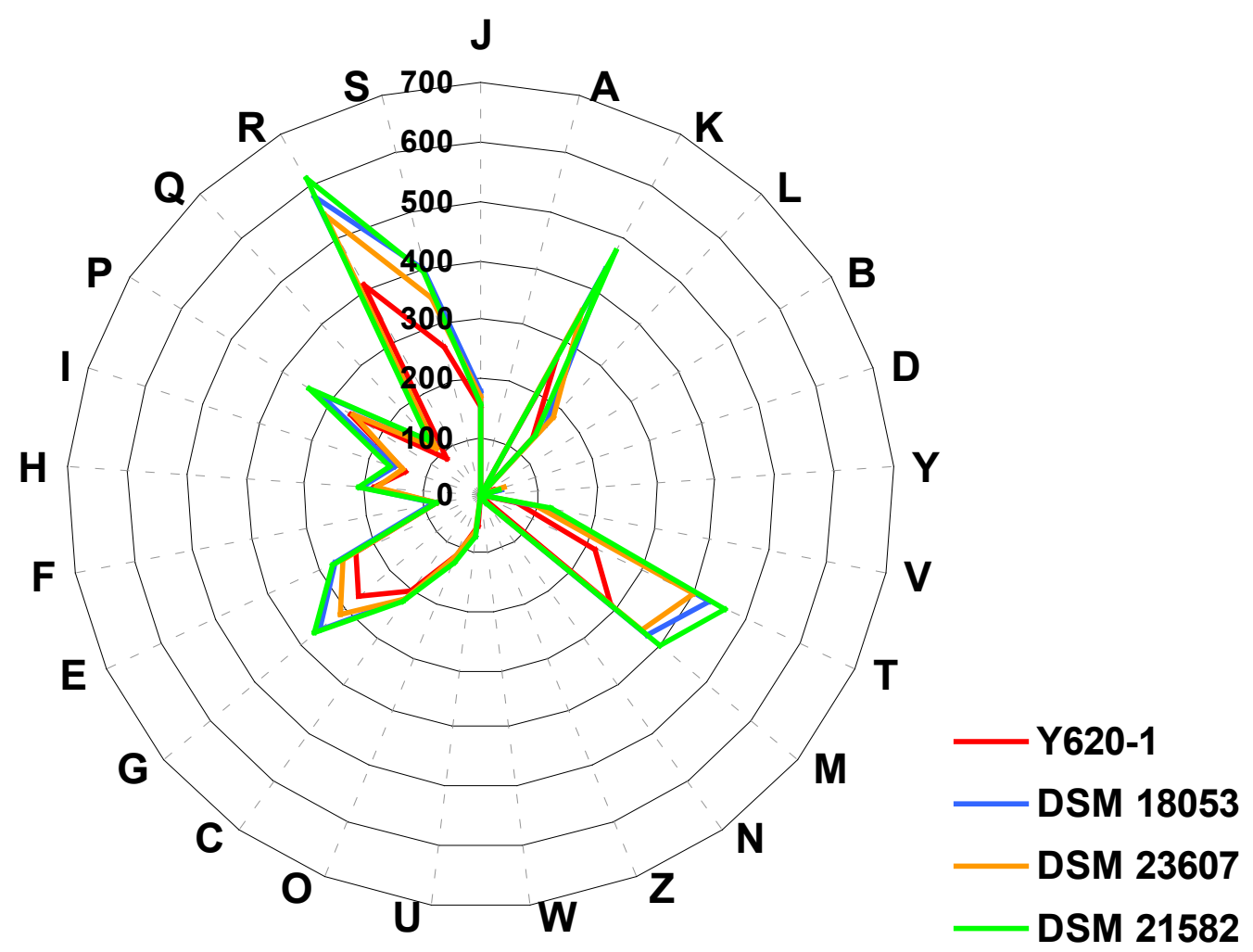

Figure 3. Distribution of COG functional categories in the genome of Dyadobacter tibetensis (T) Y620-1, D. alkalitolerans DSM 23607, D. fermentans DSM 18053 and D. beijingensis DSM 21582.

Five cold-shock proteins were found in this genome including $\operatorname{Csp} A$, GyrA, RbfA, and NusA. The proteins coded by gene $\operatorname{Rec} A, \operatorname{Rec} F, \operatorname{Rec} G, \operatorname{Rec} N$, $\operatorname{Rec} O, \operatorname{Rec} Q, \operatorname{Rad} A$ and $\operatorname{Rad} C$, which play a critical role in recombinational repair of damaged DNA, were also found [36]. Single-stranded-DNAspecific exonuclease RecJ, required for many types of recombination events [37], and CRISPRs Cas1, interacts with components of the DNA repair systems, also were found [38]. Phage shock protein C existed in the genome, which may play a significant role in the competition for survival under nutrient- or energy-limited conditions [39]. When bacteria deposit on the glacier, the low temperature, high UV radiation, and desiccation could induce the cold-shock and recombinational repair of damaged DNA proteins. Additionally, oligotrophic condition of glacial ice may induce the phage shock protein $\mathrm{C}$. The genome sequence of strain Y620-1 provides genetic information to identify the genes linked to its specific mechanisms for adaption to extreme glacial environment.

\section{Acknowledgement}

This study was financially supported by the National Natural Science Foundation of China (Grant Nos. 41371084, 41171050, 41125003, 40930526, 41025002, 40871045), Strategic Priority Research Program (B) of the Chinese Academy of Sciences (XDB03030100), and the National Basic Research Program of China (No: 2010CB951404).

\section{References}

1. Shen L, Liu Y, Yao T, Wang N, Xu B, Jiao N, Liu H, Zhou Y, Liu X, Wang Y. Dyadobacter tibetensis sp. nov., isolated from glacial ice core. Int J Syst Evol Microbiol 2013; 63:3636-3639. PubMed http://dx.doi.org/10.1099/ijs.0.050328-0

2. Chelius MK, Triplett EW. Dyadobacter fermentans gen. nov., sp. nov., a novel gram-negative bacterium isolated from surface-sterilized Zea mays stems. Int J Syst Evol Microbiol 2000; 50:751-758. PubMed http://dx.doi.org/10.1099/00207713-502-751 
Liu et al.

3. $\quad$ Baik KS, Kim MS, Kim EM, Kim HR, Seong CN. Dyadobacter koreensis sp. nov., isolated from fresh water. Int I Syst Evol Microbiol 2007; 57:1227-1231. PubMed http://dx.doi.org/10.1099/ijs.0.64902-0

4. Chaturvedi P, Reddy GSN, Shivaji S. Dyadobacter hamtensis sp. nov., from Hamta glacier, located in the Himalayas, India. Int I Syst Evol Microbiol 2005; 55:2113-2117. PubMed http://dx.doi.org/10.1099/ijs.0.63806-0

5. Chen L, Jiang F, Xiao M, Dai J, Kan W, Fang C, Peng F. Dyadobacter arcticus sp. nov., isolated from high Arctic soil on the Svalbard Archipelago, Norway. Int I Syst Evol Microbiol 2013; 63:16161620. PubMed http://dx.doi.org/10.1099/ijs.0.044198-0

6. Chun J, Kang JY, Joung Y, Kim H, Joh K, Jahng KY. Dyadobacter jejuensis sp. nov., isolated from seawater. Int / Syst Evol Microbiol 2013; 63:17881792. PubMed http://dx.doi.org/10.1099/ijs.0.043620-0

7. Dong Z, Guo X, Zhang X, Qiu F, Sun L, Gong H, Zhang F. Dyadobacter beijingensis sp. nov., isolated from the rhizosphere of turf grasses in China. Int J Syst Evol Microbiol 2007; 57:862-865. PubMed http://dx.doi.org/10.1099/ijs.0.64754-0

8. Lee M, Woo SG, Park J, Yoo SA. Dyadobacter soli sp. nov., a starch-degrading bacterium isolated from farm soil. Int J Syst Evol Microbiol 2010; 60:2577-2582. PubMed http://dx.doi.org/10.1099/ijs.0.019653-0

9. Liu QM, Im WT, Lee M, Yang DC, Lee ST. Dyadobacter ginsengisoli sp. nov., isolated from soil of a ginseng field. Int / Syst Evol Microbiol 2006; 56:1939-1944. PubMed http://dx.doi.org/10.1099/ijs.0.64322-0

10. Reddy GSN, Garcia-Pichel F. Dyadobacter crusticola sp. nov., from biological soil crusts in the Colorado Plateau, USA, and an emended description of the genus Dyadobacter Chelius and Triplett 2000. Int J Syst Evol Microbiol 2005; 55:1295-1299. PubMed http://dx.doi.org/10.1099/ijs.0.63498-0

11. Tang Y, Dai J, Zhang L, Mo Z, Wang Y, Li Y, Ji S, Fang C, Zheng C. Dyadobacter alkalitolerans sp. nov., isolated from desert sand. Int J Syst Evol Microbiol 2009; 59:60-64. PubMed http://dx.doi.org/10.1099/ijs.0.001404-0

12. Zhang DC, Liu HC, Xin YH, Zhou YG, Schinner F, Margesin R. Dyadobacter psychrophilus sp. nov., a psychrophilic bacterium isolated from soil. Int J
Syst Evol Microbiol 2010; 60:1640-1643. PubMed http://dx.doi.org/10.1099/ijs.0.017236-0

13. Lang E, Lapidus A, Chertkov O, Brettin T, Detter JC, Han C, Copeland A, Glavina Del Rio T, Nolan $\mathrm{M}$, Chen $\mathrm{F}$ and others. Complete genome sequence of Dyadobacter fermentans type strain (NS114 T). Stand Genomic Sci 2009; 29; 1(2): 133-140.

14. Priscu JC, Christner BC, Foreman CM, RoystonBishop G. Biological material in ice cores. In: Elias SA, editor. Encyclopedia of Quaternary Sciences. Volume 2: Elsevier B.V., UK.; 2007. p 1156-1166.

15. Koh HY, Lee SG, Lee JH, Doyle S, Christner BC, Kim HJ. Draft genome sequence of Paenisporosarcina sp. strain TG-14, a psychrophilic bacterium isolated from sediment-laden stratified basal ice from Taylor Glacier, McMurdo Dry Valleys, Antarctica. J Bacteriol 2012; 194:6656-6657. PubMed http://dx.doi.org/10.1128/JB.01795-12

16. Raymond JA, Christner BC, Schuster SC. A bacterial ice-binding protein from the Vostok ice core.

Extremophiles 2008; 12:713-717. PubMed http://dx.doi.org/10.1007/s00792-008-0178-2

17. Reasoner DJ, Geldreich EE. A new medium for the enumeration and subculture of bacteria from potable water. Appl Environ Microbiol 1985; 49:1-7. PubMed

18. Garrity GM, Lilburn TG, Cole JR, Harrison SH, Euzéby J, Tindall BJ. Taxonomic Outline of the Bacteria and Archaea. Release 7.7 March 6, 2007. Michigan State Univer-sity Board of Trustees 2007;DOI: 10.1601/TOBA7.7 http://www.taxonomicoutline.org.

19. Skerman VBD, McGrowan V, Sneath PHA. Approved list of bacterial names. Int I Syst Bacteriol: ASM Press; 1980. 225-420 p.

20. Ashburner M, Ball CA, Blake JA, Botstein D, Butler $\mathrm{H}$, Cherry JM, Davis AP, Dolinski K, Dwight SS, Eppig JT, et al. Gene ontology: tool for the unification of biology. Nat Genet 2000; 25:25-29. PubMed http://dx.doi.org/10.1038/75556

21. Bruno WJ, Socci ND, Halpern AL. Weighted neighbor joining: a likelihood-based approach to distance-based phylogeny reconstruction. $\mathrm{Mol}$ Biol Evol 2000; 17:189-197. PubMed http://dx.doi.org/10.1093/oxfordjournals.molbev.a 026231

22. Cole JR, Chai B, Farris RJ, Wang Q, Kulam-SyedMohideen AS, McGarrell DM, Bandela AM, Car- 
denas E, Garrity GM, Tiedje JM. The ribosomal database project (RDP-II): introducing myRDP space and quality controlled public data. Nucleic Acids Res 2007; 35:D169-D172. PubMed http://dx.doi.org/10.1093/nar/gkl889

23. Marmur J. A procedure for the isolation of deoxyribonucleic acid from microorganisms. J Mol Biol 1961; 3:208-218. http://dx.doi.org/10.1016/S0022-2836(61)80047-8

24. Delcher AL, Bratke KA, Powers EC, Salzberg SL. Identifying bacterial genes and endosymbiont DNA with Glimmer. Bioinformatics 2007; 23:673-679. PubMed http://dx.doi.org/10.1093/bioinformatics/btm009

25. Lowe TM, Eddy SR. tRNAscan-SE: a program for improved detection of transfer RNA genes in genomic sequence. Nucleic Acids Res 1997; 25:0955-0964.

26. Lagesen K, Hallin P, Rodland EA, Staerfeldt HH, Rognes T, Ussery DW. RNAmmer: consistent and rapid annotation of ribosomal RNA genes. Nucleic Acids Res 2007; 35:3100-3108. PubMed http://dx.doi.org/10.1093/nar/gkm160

27. Aziz RK, Bartels D, Best AA, Dejongh M, Disz T, Edwards RA, Formsma K, Gerdes S, Glass EM, Kubal M, et al. The RAST Server: rapid annotations using subsystems technology. BMC Genomics 2008; 9:75. PubMed http://dx.doi.org/10.1186/1471-2164-9-75

28. Benson DA, Karsch-Mizrachi I, Lipman DJ, Ostell J, Wheeler DL. GenBank. Nucleic Acids Res 2007; 36:D25-D30. PubMed http://dx.doi.org/10.1093/nar/gkm929

29. Tatusov RL, Koonin EV, Lipman DJ. A genomic perspective on protein families. Science 1997; 278:631-637. PubMed http://dx.doi.org/10.1126/science.278.5338.631

30. Kanehisa M, Araki M, Goto S, Hattori M, Hirakawa M, Itoh M, Katayama T, Kawashima S, Okuda S, Tokimatsu T, et al. KEGG for linking genomes to life and the environment. Nucleic Acids Res 2007; 36:D480-D484. PubMed http://dx.doi.org/10.1093/nar/gkm882

31. Krogh A, Larsson B, von Heijne G, Sonnhammer ELL. Predicting transmembrane protein topology with a hidden markov model: application to complete genomes. J Mol Biol 2001; 305:567-580. PubMed http://dx.doi.org/10.1006/jmbi.2000.4315

32. Bendtsen JD, Nielsen H, von Heijne G, Brunak S. Improved prediction of signal peptides: SignalP 3.0. J Mol Biol 2004; 340:783-795. PubMed http://dx.doi.org/10.1016/j.jmb.2004.05.028

33. Richter M, Rosselló-Móra R. Shifting the genomic gold standard for the prokaryotic species definition. Proc Natl Acad Sci USA 2009; 106:1912619131. PubMed http://dx.doi.org/10.1073/pnas.0906412106

34. Hothorn T, Bretz F, Westfall P. Simultaneous inference in general parametric models. Biom J 2008; 50:346-363. PubMed http://dx.doi.org/10.1002/bimj.200810425

35. Auch AF, von Jan M, Klenk H-P, Göker M. Digital DNA-DNA hybridization for microbial species delineation by means of genome-to-genome sequence comparison. 2010.

36. Kunst F, Ogasawara N, Moszer I, Albertini AM, Alloni G, Azevedo V, Bertero MG, Bessieres P, Bolotin A, Borchert $\mathrm{S}$, et al. The complete genome sequence of the Gram-positive bacterium Bacillus subtilis. Nature 1997; 390:249-256. PubMed http://dx.doi.org/10.1038/36786

37. Lovett ST, Kolodner RD. Identification and purification of a single-stranded-DNA-specific exonuclease encoded by the recJ gene of Escherichia coli. Proc Natl Acad Sci USA 1989; 86:2627-2631. PubMed http://dx.doi.org/10.1073/pnas.86.8.2627

38. Blattner FR, Plunkett G, Bloch CA, Perna NT, Burland V, Riley M, Collado-Vides J, Glasner JD, Rode CK, Mayhew GF, et al. The complete genome sequence of Escherichia coli K-12. Science 1997; 277:1453-1462. PubMed http://dx.doi.org/10.1126/science.277.5331.1453

39. Brissette JL, Weiner L, Ripmaster TL, Model P. Characterization and sequence of the Escherichia coli stress-induced psp operon. J Mol Biol 1991; 220:35-48. PubMed http://dx.doi.org/10.1016/0022-2836(91)90379-K 